TABLE 9 (continued)

\begin{tabular}{|c|c|c|c|c|c|}
\hline & $\begin{array}{r}1992-93 \\
\text { Budget }\end{array}$ & & $\begin{array}{r}1992-93 \\
\text { Budget }\end{array}$ & & $\begin{array}{r}1992-93 \\
\text { Budget }\end{array}$ \\
\hline $\begin{array}{l}\text { Xerox } \\
\text { Telephone, Fax } \\
\text { Office and Computer Supplies } \\
\text { General Administrative } \\
\text { General Operating Staff } \\
\text { Miscellaneous } \\
\text { Computer Support } \\
\text { Fees } \\
\text { Staff } \\
\text { Insurance (Workmans' Comp., } \\
\quad \text { Bonding, Travel) }\end{array}$ & $\begin{array}{r}1,000 \\
15,000 \\
12,650 \\
8,025 \\
95,306 \\
1,000 \\
\\
8,000 \\
61,118 \\
7,000\end{array}$ & $\begin{array}{l}\text { Total General Administrative } \\
\text { Building and Equipment } \\
\text { Taxes } \\
\text { Repair and Upkeep } \\
\text { Maintenance Contracts } \\
\text { Depreciation } \\
\text { Insurance } \\
\text { Utilities } \\
\text { Building Supplies } \\
\text { Custodial Staff } \\
\text { Total Building \& Equipment }\end{array}$ & $\begin{array}{r}74,000 \\
10,000 \\
28,000 \\
58,000 \\
12,000 \\
25,000 \\
7,000 \\
44,520 \\
258,520\end{array}$ & $\begin{array}{l}\text { Subtotal Expenses }^{\mathrm{h}} \\
\text { Pending Obligations } \\
\text { Annual Leave } \\
\text { Life Memberships } \\
\text { Total Pending } \\
\text { TOTAL EXPENSES } \\
\text { Revenue over Expenses } \\
\text { Expenses over Revenue } \\
\text { Reserve Fund } \\
\text { NET REVENUE }\end{array}$ & $\begin{array}{r}7,000 \\
1,000 \\
8,000 \\
2,483,285 \\
\\
(34,310) \\
55,000 \\
20,690\end{array}$ \\
\hline
\end{tabular}

${ }^{a}$ Wohlers and Quest pay fees to APSA for offering insurance and travel services to members and for APSA's assistance in making these services available to members. The CFP (Congressional Fellowship Program) is treated as a grant program.

' Retained earnings constitute the amount of earnings on APSA's investments (the Trust and Development Fund, our general cash flow reserve, and award funds) that are put directly into APSA's operating budget in accordance with APSA's By-Laws, Council policy, and procedures established by the Trust and Development Committee.

'Not including publications sponsored by the Departmental Services Program.

${ }^{d}$ Additional expenses related to the operation of organized sections are incorporated in the following other parts of this budget: Annual Meeting, Membership, Business Office, PS, Governance, General Administration.

'These expenses do not include the in-kind contributions of the University of Rochester, including overhead, equipment, graduate assistants, and relief-time for the Managing Editor.

${ }^{\mathrm{f}}$ COGS (Cost of Goods Sold) is an accounting technique that charges the expense side of the budget for the value of the publications sold in the fiscal year. Unsold publications are listed as inventory and counted as a depreciating asset in our annual audit.

${ }^{8}$ National Humanities Alliance, Consortium of Social Science Associations, American Council of Learned Societies, Social Science Research Council, American Association for the Advancement of Science, American Council on Education, International Political Science Association, American Association for the Advancement of Slavic Studies, Council of Professional Association on Federal Statistics, National Coordinating Committee for the Promotion of History, Coalition for National Science Funding. APSA is a member of, but pays no dues to: SSRC, AAASS, and CNSF.

${ }^{\text {h}}$ The following programs have independent funding and budgets, and they are reflected in APSA's annual audit: Kirkpatrick Fund, Congressional Fellowship Program, Ralph Bunche Summer Institute, IBM Poliware, other outside grants (these vary from year to year and fund activities, APSA staff, and administrative expenses). FIPSE-Course Syllabi Collection Project, Pew Charitable Trusts-Bill of Rights Education Collaborative Faculty Workshops, Japan-U.S. Friendship Commission-Japan Workshops, MacArthur-South Africa Workshop, NSF Workshop on Data Analysis, NSF/Argonne National Laboratory-Global Warming Conference.

\section{Report of the Managing Editor of the American Political Science Review, 1991-92}

\section{G. Bingham Powell, Jr. University of Rochester}

Fiscal year 1991-92 was a time of transitions for the $A P S R$. This report is divided into sections corresponding to the three major transitions: to a new managing editor and new editorial staff in Rochester; to a new format and a new press; to a new Book Review editor and editorial staff in Austin.

\section{Transition of Managing Editors}

Ohio State to Rochester. Pat Patterson completed six years of outstand- ing service to the profession as managing editor of the $A P S R$ at the end of the summer of 1991. After careful discussion about the mechanics of transition, we arranged a several-stage transfer of responsibility from Pat and his staff at Ohio State to the new editorial team in Rochester. The general concept was for Pat and Ohio State to continue editing all the 1991 issues and turn over responsibility to Bing Powell and Rochester for the March 1992 issue.

After the December 1991 issue was filled, in late June 1991, Pat began to send all manuscripts and referee reports that were not obvious rejects, to Rochester for final decision (accept, revise and resubmit, reject). These were manuscripts that would be the basis for the March 1992 and subsequent issues. Ohio State continued through the summer to reject manuscripts where the referees clearly advised against publication, largely a mechanical task. Ohio State also continued to receive all new manuscripts and assign them to referees through the summer. After about August 15 new manuscripts were sent to Rochester, where the new editorial team was being assembled. Ohio State also continued through the fall semester all the work involving the December 1991 issue, including the copy-editing and handling of galley proofs, page proofs, and blue lines. Michael Lane, who has been copyediting the Review for the past five years at Ohio State, continued as copy editor for the new Rochester team for the 1992 issues.

In general the transition procedure worked very well. I want to express my appreciation to Pat Patterson for arranging a transition that allowed 
the Rochester team some gradual exposure to the various phases of the duties of managing editor: manuscript decisions, referee assignments, copy editing, and production. We are also grateful to his associate editor, Christine Harrington, for her advice on innumerable matters of detail.

The Flow of New Manuscripts. The first year of a new managing editor typically sees an increased number of manuscript submissions. Dina Zinnes received 407 manuscripts in her first year, a number that dropped to 380 the following year. Patterson received 545 new manuscripts of all kinds in his first year as managing editor, a number that dropped to 427 in the second year and stayed constant at about that rate through his subsequent five years as managing editor As shown by Table 1, 1991-92 proved no exception to this rule. In 1991-92 Ohio State (in July and August) and Rochester (from August 15 to June 30 ) received 480 new manuscripts. This number is up about $10 \%$ from 1990-91, consistent with the usual first-year bulge. Over 40 manuscripts were received in the months of September, October, March, April, and June.

As Table 1 also shows, the distribution of manuscripts across fields is roughly consistent with previous years, with the pleasant exception of a notable increase in manuscripts in international relations, up from 9 or $10 \%$ in previous years to $14 \%$ of the manuscripts submitted in 1991-92. American politics (including political behavior and public policy) saw a slight decline in its usual dominance of manuscripts, from $39 \%$ to $34 \%$. In absolute terms these figures reflect a remarkable increase from the previous year in international relations from 39 to 67 manuscripts. Normative theory also saw an increase of some 25 manuscripts, while there were eight fewer manuscripts submitted in American politics. It is hard to know if these are serious trends or statistical fluctuations, but I certainly hope that the international relations community is returning to view the $A P S R$ as a major publication vehicle.

\section{The Acceptance of Manuscripts.}

Table 2 shows the distribution across fields in manuscripts accepted for publication. These include the 53 pieces (articles, notes, and controversies) published in March, June, and September, 1992, and those accepted and tentatively scheduled for publication in December 1992. (The Presidential Address in March is not counted.) As the Ohio State team continued with full responsibility for the 1991 issues, and those decisions were almost entirely completed before June 30, they are not included here. (For obvious reasons, parts of each of the 1992 controversies published in this period had earlier origins, but they involved at least some decision making on the part of the current managing editor.) The distribution of published manuscripts parallels roughly the distribution of manuscripts submitted across the subfields, consistent with previous experience. Fiscal year 1988-89 is also shown for comparison, as it is slightly more typical in terms of the num- ber of manuscripts than are the 1990-91 figures.

Of course, because of lags in accepting and publishing manuscripts, as well as the fact that a large percentage of published manuscripts go through a "revise and resubmit" stage, the distribution of manuscripts published reflects at least in part the manuscripts submitted in the previous year. For this reason, Table 3 , showing acceptance rates across subfields, is always somewhat problematic.

As described in their annual reports, previous managing editors have adopted different approaches to calculating the acceptance rates. None of the approaches is perfect. Each is a fair approximation of true acceptance rates if submission rates in the different fields are fairly steady from year to year. Dina Zinnes seems to have reported the acceptance rates on manuscripts

\section{TABLE 1}

Distribution of Manuscripts Submitted to the APSR by Field in 1990-91 and 1991-92

\begin{tabular}{lcc}
\hline Field & $\begin{array}{c}1990-91^{\mathrm{a}} \\
\%^{-}\end{array}$ & $\begin{array}{c}1991-92 \\
\%\end{array}$ \\
\hline American Politics and Public Policy & 39 & 34 \\
Comparative Politics & 22 & 20 \\
Normative Political Theory & 17 & 21 \\
International Relations & 9 & 14 \\
Formal Theory & 13 & 10 \\
Total & 100 & 99 \\
\hline Number of Manuscripts & 438 & 479 \\
\hline
\end{tabular}

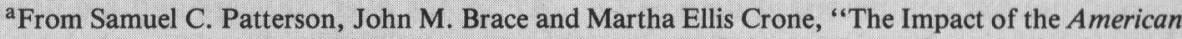
Political Science Review," PS, 24 (December 1991), p. 766, Table 1. Manuscripts submitted include both new manuscripts and revise/resubmits. 1991-92 figures include 50 of the latter.

\section{TABLE 2}

Distribution of Manuscripts Accepted by the APSR by Field in 1988-89, 1990-91 and 1991-92

\begin{tabular}{|c|c|c|c|}
\hline Field & $\begin{array}{c}1988-89^{a} \\
\%\end{array}$ & $\begin{array}{c}1990-91^{\mathrm{a}} \\
\%\end{array}$ & $\begin{array}{c}1991-92^{b} \\
\%\end{array}$ \\
\hline American Politics and Public Policy & 36 & 42 & 34 \\
\hline Comparative Politics & 20 & 23 & 17 \\
\hline Normative Political Theory & 18 & 13 & 24 \\
\hline International Relations & 11 & 7 & 13 \\
\hline Formal Theory & 15 & 16 & 11 \\
\hline Total & 100 & 101 & 99 \\
\hline Number of Manuscripts & 55 & 31 & 53 \\
\hline
\end{tabular}


aid in the process of finding referees. In 1991-92 I introduced a process of consulting with the editorial board about referees, not just in special cases but in a routine fashion on nearly every manuscript. This process required, however, care and dedication from the $A P S R$ graduate student interns as well as from our exceptionally dedicated and helpful editorial board.

When a manuscript was received, it was logged in and then assigned to a graduate student intern. The intern read the manuscript, and prepared an Editorial Board Referral Sheet that included: brief précis, a list of special questions and comments, and a short list of possible referees. The list of questions/comments typically included information about the technical demands of the manuscript (Greek, statistics, country knowledge, etc.), the unavailability of obvious referees, and other information about the relationship of the manuscript to the field that might not be clear from précis and abstract. After my approval, changes and suggestions, the Editorial Board Referral Sheet and the manuscript's abstract were sent by FAX to an appropriate member of the Editorial Board (occasionally to two members). The editorial board member then responded by FAX, indicating the appropriateness of our proposed referees, making additional suggestions, and offering interpretative advice. The intern suggested referees based on this FAX and referee records and availability. I made my final selection of referees based on all this information. In addition to this direct consultation on specific manuscripts, the editorial board members helped make final decisions in some difficult cases (even reading some manuscripts whose technical demands exceeded my capacity) and worked with us to develop lists of referees for different subfields.

Naturally, on occasion I consulted as well with other professional colleagues, in my department and outside it, for additional advice on referee selection.

While no system can be perfect, as various authors will testify, I think that this new approach resulted in the selection of a wide range of competent referees across all the subfields. In fact, in 1991-92 the Rochester office sent over 1,200 letters seeking advice, to 830 different individuals. (This does not count solicitations from Ohio State for the 68 manuscripts they received in July and August.) As best I can tell from the scattered comments in previous managing editor reports, this may be the largest number of referees consulted in a given year in APSR history. As best I can tell from reading the results, we generated an extraordinarily large number of competent analyses and recommendations. I hope that these help us not only to choose the best manuscripts, but to give helpful advice to the vast majority of manuscripts that we could not accept. Many of the latter (about $50 \%$ according to a study done by Patterson) are eventually published in another scholarly forum. I must express my appreciation to the many scholars who participated in the "Seminar by Mail" (to use Patterson's term) in 1991-92.

However, these new procedures were time consuming to develop and sustain. In conjunction with our general inexperience, staff illness, and the other transitions discussed below, the consequence was the one part of our first year record of which I am not proud: the manuscript processing time. As shown in Table 4, the average turn-around time on manuscripts was over two weeks longer than the average in Patterson's first two years and about a month longer than the average for Patterson's last four years. The average turn-around time was about 72 working days (calendar days multiplied by $5 / 7$ 's for comparability to Patterson's figures), in comparison to Patterson's 59 days in 1985-86 and 51 days in 1990-91. Our numbers are roughly similar to the figures reported by Dina Zinnes in her first year (71 days, using the $5 / 7$ multiplier).

The subtotals reported in Table 4 in comparison to Patterson are of some interest. It is obvious that manuscripts spent much too long in our $A P S R$ office. (The 26-day figure does drop substantially by the end of the year, indicating that some learning took place.) Once the manuscripts went out, the time in the hands of referees was quite good, nearly comparable to Patterson's recent years and better than the initial years when he, like us, had less experience with nagging slow referees and replacing others. Perhaps too optimistically, I interpret the reasonably good referee response times as reflecting our selection of referees who usually felt competent to evaluate the manuscripts they received. (I hope the times continue and even improve.)

\section{Steps to Improve Turn-around Time.} The long time the average manuscript spent in our office was the product, I think, of five factors: (1) inexperience (e.g., developing sys-

TABLE 4

Elapsed Time in the APSR Review Process (Work Days)

\begin{tabular}{|c|c|c|c|c|c|c|c|c|c|}
\hline Processing Stage & $1981-82$ & $1982-83$ & $1985-86$ & $1986-87$ & $1987-88$ & $1988-89$ & $1989-90$ & $1990-91$ & 1991-92 \\
\hline From receipt to referee assignment & - & - & 4 & 7 & 11 & 12 & 11 & 9 & 26 \\
\hline From assignment to last review & - & - & 53 & 47 & 35 & 37 & 39 & 42 & 44 \\
\hline From last review to decision & $\overline{-1}$ & - & 2 & 4 & 5 & 8 & 6 & 6 & 9 \\
\hline From receipt to final decision & 71 & 64 & 59 & 58 & 49 & 52 & 52 & 51 & 72 \\
\hline
\end{tabular}


tematic procedures for monitoring the progress of manuscripts within the office); (2) innovative procedures (it took a while to discover what questions to ask the editorial board members and to use FAX, rather than telephone or electronic mail, to communicate with them); (3) too few APSR interns, especially during a two-month period when one of them was incapacitated by serious illness; (4) inadequate referee lists in some areas; and (5) editorial board delays. The first two were inevitable and have been largely, I hope, overcome. We have taken steps to alleviate the others by adding a third intern to the APSR staff for 1992-93, working with the editorial board to develop referee lists in areas of greatest need, and adding several additional members to the editorial board.

I hope that 1992-93 will see a marked improvement in average time of manuscript processing. I think that the high quality of referee selection encouraged by the editorial board consultation is worth a week's additional time, which is compensated, at least in part, by the faster referee responses. But minimizing the turn-around time, especially for rejected manuscripts, has to be an important challenge for every $A P S R$ managing editor.

\section{Transition in Format and Press}

Format Change: $A$ Larger Size Review. For the readership of the APSR the most obvious transition was to the new, larger format of the journal. The change to the $81 / 2$ " by 11 " size was initially proposed by the APSA staff and was supported in a recommendation from the APSA's publications committee. The new size saves substantially on paper costs, as trimming and wastage are no longer necessary. The savings have been used in part to contain costs, especially those posed by rising paper prices, and in part to support an expansion of the size of the Review. The increase in size of about $10 \%$ has thus far been used to deal with backlogged book reviews; the eventual plan is to increase the size of the Book Review by about $10 \%$, with probably a smaller increase in the size of the article section. The larger page size makes it easier to print readable equations, figures, and tables. For all these reasons the change to the new format has been desirable, despite the sadness that I and other admirers of the Review's traditional distinctive size and format felt at seeing the demise of the latter.

The larger size required some design changes. I am grateful to Sheilah Mann of APSA and Electronic Type for their work in developing these. For the most part, however, we tried to stay close to the excellent format developed by Pat Patterson and earlier managing editors.

The change to a larger size of paper was also accompanied by a change in the paper itself. I did not recognize that a change in the nature of the paper was also required by the increasing paper costs. A press error in selecting the paper for the first issue, using a glossy instead of the stipulated flat finish, created a first issue that was difficult for many subscribers to read. The finish error was corrected in June, but we continue to search for a paper whose weight, whiteness, and quality will best combine readability and cost containment.

Other than the paper problem, the transition to the larger size paper has gone relatively smoothly. We continue to learn how to exploit fully the additional flexibility created by the larger size pages. But, in general, I think the transition has been successful, if not without pain, with advantages that will be substantial in the long run.

Change in Press. We also changed presses in 1991-92. For a variety of reasons we felt that Byrd Press, which also prints $P S$, could provide us with better technical capacity and attention than had been available. Those expectations have been realized. For example, the time from submitting manuscript copy until the journal appears has been reduced by over a month, enabling more timely appearance of articles and book reviews. It will also be possible, beginning we hope in December 1992, to mail $P S$ and the $A P S R$ together, with a substantial savings in mailing costs.

Inevitably, however, the combination of a new press and a new editorial team, as well as the new page format, meant that neither could give the other the guidance that would have been desirable in the complexities of transforming manuscript copy into printed journal pages. The March 1992 issue reflected this mutual learning process, especially in the occasionally uneven handling of tables and figures, which are perhaps the most challenging element among our special production problems. However, we believe that most of these "teething troubles" have now been overcome. I want to express here my thanks to $A P S R$ assistant (now associate) editor Linda Lindenfelser for her tireless efforts in working with Byrd Press in solving the innumerable production issues.

\section{Transition in the Book Review}

The Book Review is a large and important part of the APSR, and by all accounts is the most widely read section of the Review. The task of the Book Review editor is large and important. To receive nearly 2,000 books, choose those appropriate for review, solicit reviewers for them (either individually or as part of several-book reviews) and process the returning manuscripts requires competence, imagination, and dedication. I was extremely glad when Melissa Collie of the University of Texas at Austin agreed to assume these challenging responsibilities.

The transition period for the Book Review began July 1, 1991. Professor Collie assumed full responsibility as Book Review editor on September 1, 1991. Her work in receiving books and assigning reviewers was done entirely autonomously at the University of Texas. Because of the backlog from the previous year, as well as the usual processing time, all of the book reviews and review essays appearing in 1991-92 (September through June) were the work of her predecessor, Helen Ingram of the University of Arizona. The distribution of book reviews by field appearing in the Review during that period is shown in Table 5.

The review assignments by Collie in 1991-92 are shown in Table 6. As the table shows, 1,743 books were received by the Book Review in 
1991-92, and 468 were selected for review. This number is (by chance) identical to the 468 that appeared in the APSR during that time, shown in Table 5, and about the same proportion that has been reviewed in recent years. As the table also shows, the distribution of books reviewed is roughly shaped by the distribution of books received in the various fields.

The results of Collie's review assignments began to appear in the September 1992 issue. We are all fortunate to have the benefit of her excellent work.

\section{Overview Comments}

In retrospect it was probably unwise to attempt so many transitions in a single year. Despite ideal cooperation between the managing editors, and strong support from Cathy Rudder, Sheilah Mann, and Robert Hauck at APSA, the sheer complexities of the transition were substantial. The new Rochester team had its hands full learning to manage its inherited procedures, not to mention adding the complex procedures of editorial board interaction. Associate editor Linda Lindenfelser and my first $A P S R$ interns, David Hayes and Fiona McGillivray, earned their spurs under extraordinarily difficult circumstances and I want to express my apologies, as well as my gratitude, to them.

We were too inexperienced to give the new press all the assistance it could have used in adapting to the special challenges of $A P S R$, especially in the areas of graphs and figures. The format change created further complexities and demands for all concerned. In consequence, there were some ragged edges in the appearance and quality of the first few issues. Nor did we foresee adequately the problem of selecting the correct paper. We are also responsible for an undesirable increase of a month in the average turn-around time of manuscript processing. However, having survived the transitions and learned much from them, we are in a stronger position to meet the challenges of the forthcoming year. I think that we are providing authors with good reviews, which I hope will become more timely. Most important, I believe that the APSR is publishing the best and most important scholarship in political science.
TABLE 5

APSR Book Review: Report on Books Reviewed, by Field September 1991-June 1992

\begin{tabular}{|c|c|c|c|c|c|c|c|c|}
\hline \multirow[b]{2}{*}{ Issue } & \multicolumn{2}{|c|}{ Theory } & \multicolumn{2}{|c|}{ American } & \multicolumn{2}{|c|}{ Comparative } & \multicolumn{2}{|c|}{ IR } \\
\hline & $\%$ & $(\mathrm{~N})$ & $\%$ & $(\mathrm{~N})$ & $\%$ & $(\mathrm{~N})$ & $\%$ & (N) \\
\hline September 1991 & 24.8 & (25) & 32.7 & (33) & 24.8 & (25) & 17.8 & (18) \\
\hline December 1991 & 23.5 & (19) & 25.9 & (21) & 34.6 & (28) & 16.0 & (13) \\
\hline March 1992 & 24.0 & (35) & 34.9 & (51) & 24.0 & (35) & 17.1 & (25) \\
\hline June 1992 & 18.6 & (26) & 31.4 & (44) & 27.9 & (39) & 22.1 & (31) \\
\hline
\end{tabular}

Note: Reviews appearing in all these APSR issues (September 1991-June 1992) were commissioned exclusively by the Book Review Office at the University of Arizona. N's include books reviewed in review essays and multiple- and single-book reviews.

\section{TABLE 6}

APSR Book Review: Report on Books Processed by Field Summer, 1991 to July 1, 1992

\begin{tabular}{lccc}
\hline Field & Books Received & \multicolumn{2}{c}{$\begin{array}{c}\text { Books Reviewed } \\
\text { or Scheduled } \\
\text { for Review }\end{array}$} \\
\cline { 3 - 5 } & 273 & $\%$ & $(\mathrm{~N})^{\mathrm{b}}$ \\
\hline Political Theory & 547 & 30.0 & $(82)$ \\
American Politics & 642 & 29.6 & $(162)$ \\
Comparative Politics & 281 & 21.8 & $(140)$ \\
International Relations & 436 & 29.9 & $(84)$ \\
Average per Field & 1,743 & 26.9 & \\
Total Number of Books & & & 468
\end{tabular}

${ }^{a}$ These are books that have been processed by the Book Review Office at the University of Texas. They were either sent to the UT Office from Arizona or directly from the publishers. Excluded are books that were still being handled by Arizona in the summer and fall of 1991 as well as approximately 130 books that the UT office received too recently to be included in the table.

${ }^{\mathrm{b}}$ The $\mathrm{N}$ is the number of books for which invitations to receive have been issued. Reviews commissioned by the UT office began to appear in the September 1992 issue of the APSR. 